\title{
The Social Capital-Control Nexus: Lessons From Implementation of Accounting Control Systems in Two Chinese Organizations
}

\author{
Gary Pan \\ School of Accountancy, Singapore Management University \\ 60 Stamford Road, Singapore 178900 \\ E-mail: garypan@smu.edu.sg
}

Received: May 13, 2018

Accepted: May 25, 2018

Published: June 13, 2018

doi:10.5296/ijafr.v8i2.13134

URL: https://doi.org/10.5296/ijafr.v8i2.13134

\begin{abstract}
One common theme of Accounting Control System project failure centers on inadequate or inappropriate enactment of effective controls during project implementation. As Accounting Control Systems projects are viewed by many as a social process involving managing relationships among multiple stakeholders with diverse backgrounds and capabilities, there is a growing number of IS researchers that have utilized the social capital theory to examine the enactment of clan control during system implementation. Despite the growing interests, relatively little is known about the relationships between social capital and the formal as well as informal controls. Also, the moderating impact of social capital attributes interaction on social capital-control relationship also remains unknown. Employing concepts from control and social capital theories, this paper contributes to Accounting Control Systems implementation research by uncovering two types of social capital-control relationship with supporting case evidence - supplementary and synergistic. We also identified moderating effects on the social capital attributes interaction on the relationship with behavioral as well as clan controls. We conclude with suggestions for future research.
\end{abstract}

Keywords: Accounting control systems implementation, Social capital, Control, China

\section{Introduction}

Information systems (IS) implementations in organizations have grown in size and complexity as organizations attempt to leverage IS as a strategic business enabler that may provide significant value to the business. While IS have become an increasingly important 
and integral part of businesses, coping with complex information systems implementation projects has been a central problem for the field of IS and its practice for decades (Jiang \& Klein, 1999). Despite advances in software engineering, many organizations continue to experience IS project failures (Kappelmana et al., 2006). One common theme of IS project failure centers on inadequate or inappropriate enactment of effective controls during IS implementation (Kirsch, 2004; Liu et al., 2010). Research has shown that control strategies play a critical role in effective project management and have significant impacts on IS project success (Kirsch, 1996). IS project is not merely a technical exercise, but also a social process involving managing relationships among multiple stakeholders with diverse backgrounds and capabilities. IS project is viewed a set of "socially defined ways" to achieve a defined outcome and create the basis for responding appropriately to individual circumstances (Ashurst et al., 2008). As such, control is one relevant and important approach managers use to ensure project progress by motivating individuals to work in accordance with organizational goals and objectives (Kirsch, 2004).

In general, control refers to any attempt to motivate individuals to act in a manner that is consistent with organizational objectives (Ouchi, 1980; Eisenhardt, 1985; Kirsch, 1997). Kirsch (1997)'s definition of formal and informal control modes has been widely established and adopted as the de-facto model of choice when control is discussed in IS implementation studies. According to Kirsch, formal controls involve the specification and evaluation of behaviors or outcomes, coupled with appropriate rewards or sanctions. In settings where teamwork is prevalent, informal controls may supplement or possibly replace formal hierarchical approaches to control. As project teams are more than simply collections of individuals, and social factors play an important role in team phenomena, therefore, it is common to see control mechanisms used in IS projects by the controller to ensure that the controllee conforms to "socially defined ways" during IS implementation.

In recent years, several studies have examined the topic of control within IS project setting. For instance, Rustagi et al. (2008) focused on formal control modes as they examined the predictors of formal control usage in information technology (IT) outsourcing partnerships. In a study conducted in 2010, Kirsch and her colleagues developed and tested an integrated model of team-based clan control using social capital as a predictor. They explored and highlighted social capital, that reflects connections and relationships among individuals may have an important impact on clan control strategies during IS project setting. Chua et al. (2012) went further by examining how to enact clan control in complex IT projects. The authors suggested that the enactment of clan control is a dual process involving the development of social capital dimensions and reinforcement of shared values, beliefs and norms.

To date, while much has been discussed on social capital and clan control, relatively little is known about the associations between social capital and the formal and informal control modes - an issue that is viewed important to ensure project progress and success (Kirsch et al., 2010) especially when team members, as well as team managers, can leverage social capital assets to facilitate control within project teams. Furthermore, little is known about the moderating impact of social capital attributes interaction on social capital-control relationship. 


\section{MlMacrothink}

International Journal of Accounting and Financial Reporting

ISSN 2162-3082

2018, Vol. 8, No. 2

To address the knowledge gap, we conducted a multiple case study to address the following two research questions: (1) how are social capital attributes associated with formal as well as informal controls? And (2) what are the moderating impact of social capital attributes interaction on social capital-control relationship?

\section{Theoretical Foundation}

\subsection{Control in IS Implementation}

There is a significant body of evidence that control strategies play a critical role in effective project management and have significant impacts on IS implementation success (Kirsch, 1996; 1997; Tiwana \& Keil, 2007). According to Kirsch (1997), controls used in IS project settings can be categorized into formal and informal control modes. Table 1 below provides a summary of these control modes.

Table 1. Definition of formal and informal control mode in IS Project Context - Adapted from Kirsch (1997)

\begin{tabular}{lll} 
Mode & \multicolumn{1}{c}{ Type } & \multicolumn{1}{c}{ Definition } \\
Formal & Behavior & $\begin{array}{l}\text { The act of setting a set of specific rules and procedures that aligns the } \\
\text { behavior of the controllee to whatever is deemed desirable in meeting the } \\
\text { organization's objective }\end{array}$ \\
\cline { 2 - 3 } & $\begin{array}{l}\text { Control } \\
\text { Outcome }\end{array}$ & $\begin{array}{l}\text { The act of setting goal that is desirable in meeting the organization's objective } \\
\text { and a reward is given to the controllee who meets it }\end{array}$ \\
\hline Conformal & $\begin{array}{l}\text { Clan } \\
\text { Control }\end{array}$ & $\begin{array}{l}\text { Looks at the dissemination of desired value, belief and philosophy of the } \\
\text { organization by socializing the individuals to a common set of norms and } \\
\text { values within a clan }\end{array}$ \\
\cline { 2 - 3 } & $\begin{array}{l}\text { Self } \\
\text { Control }\end{array}$ & $\begin{array}{l}\text { Looks at mechanism that identifies and provides the conducive environment } \\
\text { that rewards and encourages highly motivated individual or group of } \\
\text { individuals to exercise self-control in the best interest of meeting the } \\
\text { organization's objective }\end{array}$ \\
\end{tabular}

During IS implementation, it is inevitable for controller to apply some forms of control mechanisms over the controllee to assure the conformance towards IS implementation objectives. In recent years, the topic of control within IS project setting has been studied in several angles. Kirsch and her colleagues (2002) explored IS project control from the client's perspective and suggested that formal and informal control can be exercised across various types of organizational relationships between the controllers and controllees. The controller will maintain a portfolio of control modes and apply them in combination as a whole (Choudhury \& Sabherwal, 2003). Kirsch (2004) examined how and why stakeholders exercise different controls during different phases of large IS projects and concluded control is exercised differently in each development phase. According to their study, factors in the 
project, stakeholder, and global contexts may trigger changes in control choices from one project phase to another. Rustagi et al. (2008) focused on formal control modes as they examined the predictors of formal control usage in IS outsourcing partnerships. In their study, the authors define the amount of formal control as the variety of mechanisms used by a client to exercise control over a vendor and the extent to which the mechanisms are used. Behavior control in the context of software development is exercised through the specification of methods for tasks such as project management, analysis, design, programming, testing, and documentation (Kirsh, 1996). Outcome control in software development activities is exercised through the specification of benchmarks, quality metrics, and performance criteria, such as productivity standards, budgets, and schedules.

In recent years, several controls researchers have delved deeper into clan control domain. In a study conducted in 2010, Kirsch and her colleagues developed and tested an integrated model of team-based clan control using social capital as a predictor. In that paper, Kirsch and her colleagues suggested formal controls, with their focus on pre-specified rules, performance targets and hierarchical relationships may be less effective in a teamwork environment and individuals in a team may be more inclined to be motivated by shared norms and values, as well as a common vision. They highlighted social capital, that reflects connections and relationships among individuals may have an important impact on clan control strategies during IS development. Even though Kirsch et al. (2010) adopted social capital as a predictor of team-based clan control, they did not mention how clan controls may be enacted. To address the knowledge gap, Chua et al. (2012) subsequently examined how to enact clan control in complex IS projects. In their study, the authors suggested that the enactment of clan control is a dual process involving the development of social capital dimensions and reinforcement of shared values, beliefs and norms.

So far, these Control studies have confirmed the fact that there is an association between social capital and informal control modes. Nevertheless, whether there is association between social capital and formal control modes remains unclear. Furthermore, the nature and extent of relationship between social capital and informal control modes also have yet to be explored. It is possible that the three attributes of social capital interact to affect both formal and informal control. Certainly this is an important area to study especially when the effectiveness of a control mechanism is dependent upon the relationship between controller and controllee (e.g., Das \& Teng, 1998; Inkpen \& Currall, 2004) and team members, as well as team managers, may well leverage social capital assets to facilitate control within project teams (Kirsch et al., 2010).

\subsection{Social Capital in IS Implementation}

Bourdieu (1986) defines social capital as "the aggregate of actual or potential resources which are linked to possession of a durable network of more or less institutionalized relationships of mutual acquaintance or recognition" (pp. 248). Nahapiet and Ghoshal (1998) categorize social capital into three clusters: structural, relational and cognitive. The structural cluster represents connections among individuals and how openly and freely they share information. The focal point of this dimension includes network ties and configuration. 


\section{Mll Macrothink}

International Journal of Accounting and Financial Reporting

ISSN 2162-3082

2018, Vol. 8, No. 2

Network ties may provide access to resources and connection among members of an organization (Nahapiet and Ghoshal, 1998). Network effects are influenced by three pairs of social network ties: (1) the direct and indirect network ties (Hansen, 2002); (2) the internal and external network ties (Adler and Kwon, 2002), and (3) the strong and weak network ties (Hansen, 2002). These social network ties may affect resource accessibility and exchange among the users to accomplish their tasks. In terms of network configuration, Nahapiet and Ghoshal (1998) recognize the influences of network structure, such as density, connectivity, and hierarchy on the information exchange through different levels of network. Actors with rich and diversified networks can enjoy the benefit of having more access to information.

In terms of relational cluster, it refers to assets that are created and leveraged through relationships that include attributes such as: trust and norms (Nahapiet \& Ghoshal, 1998). Trust is a necessary pre-condition in successful network relations and is known as essential lubricant to all social activities as social capital thrives on authenticity (Cohen \& Prusak, 2001). Leana and Van Buren (1999) also suggest that social capital is a resource of social relations within the organization that can be realized through shared trust that facilitates successful collective action. Norms represent the degree of consensus in the network (Coleman 1990), in other words, they are unstated rules that influence the behavior of the network members. Norms facilitate cooperation and motivate actors to engage in exchange processes (Putnam 1993). They resolve the problems of collective action because they can influence behavior of all members towards the common goal, thus forging a common identity and commitment to the common good. Norms also help bind communities and transform egocentric individuals into members of a community with shared interests.

The cognitive cluster represents a shared system of meaning in which a collective understanding can develop. Cognitive dimension represents shared understanding, interpretations, and systems of meanings among parties (Nahapiet \& Ghoshal, 1998). Inkpen and Tsang (2005) consider two facets of the cognitive dimension: shared goals and shared culture among network members. Shared goals represent the degree to which network members share a common understanding and approach to the achievement of network tasks and outcomes. Tsai and Ghoshal (1998) use the term shared vision, which embodies the collective goals and aspirations of the members of an intracorporate network. Inkepen and Tsang (2005) contend that when a shared vision is present in the network, members have similar perceptions as to how they should interact with one another. This can promote mutual understandings and exchanges of ideas and resources.

As IS projects become prevalent, it is important to mobilize social capital in IS implementation processes, especially in terms of providing shared goals and culture, supporting individual creativity and building trusts in the community. Controllers such as project managers often have to get various stakeholders [e.g., business unit (B.U.) representatives, consultants, IT personnel], who are controllees, to work together to deliver the project. These stakeholders do better work if they share overall group objectives and adhere to group values and norms. However, stakeholders may come from distinct communities that may be working together for the first time at the start of the project. 


\section{MInstitute ${ }^{\text {Macrothink }}$}

International Journal of Accounting and Financial Reporting

ISSN 2162-3082

2018, Vol. 8, No. 2

To date, while much has been discussed on social capital and control, relatively little is known about the associations between social capital and the formal and informal control modes - an issue that is viewed important to ensure project progress and success (Kirsch et al., 2010) especially when team members, as well as team managers, can leverage social capital assets to facilitate control within project teams.

\section{Research Approach}

We adopted a qualitative research approach with multiple case design in order to ensure exposure to different control modes implemented in IS projects. The selection of the cases was guided by the principle of theoretical replication (Yin, 1994). We selected and successfully obtained access to two case sites and carried out extensive primary and secondary data collection. The organizations involved in this study comprised two Chinese private organizations: Beijing Capital International Airport and Haier Group. We selected Terminal 3 of Beijing Capital International Airport (BCIA) because it is interesting to study how BCIA enacted a set of controls within a large IS implementation project initiated to meet the large number of visitors for 2008 Beijing Olympics. Due to the project's tight deadline of 2 years, it was a daunting task involving the implementation of several large complex systems and coordination of several stakeholders. In our case study, four large-scale mission-critical systems were featured. These four systems were selected because of their sheer size of implementation, their complexity in dealing with large group of internal and external stakeholders (e.g. airlines' staff, custom officers, IT staff, business units' personnel, vendors and/or government agencies personnel) and of their mission criticality to the whole Terminal 3 program.

For Haier Group, we selected the largest household appliances manufacturer in China, as our case company for two reasons. Firstly, the company excels in fulfilling a large amount of sales orders in a short time, which indicates its superior capability in managing daily operations - interesting phenomenon. Secondly, given the large scale of sales and production in the company, the capability to process information becomes particularly crucial to support its operational decision-making. While both cases have similar characteristics to some extent in that they are world renown large size Chinese corporations involving large-scale IT systems, we sought variation in other characteristics to tease out further compelling evidence. For example, the approaches to control enactment within IS implementation were different in the two cases. BCIA adopted a good mix of both formal and clan controls but Haier relied heavily on formal controls. Our goal was to expand and generalize theories and not statistical generalization (Yin, 1994).

\subsection{Data Collection}

For both cases, we conducted primary and secondary data collection. For BCIA, field research began in June 2009. Altogether 27 face-to-face interviews were conducted with 27 key personnels. Each interview lasted 120 to 180 minutes on average. Interviewees included General Manager of Information Department at BCIA, Deputy Manager, Project Manager, System Service Engineers, Business Managers and other relevant project stakeholders. For Haier, data collection started between September 2010 and December 2011. Interviewees 


\section{Mll Macrothink}

International Journal of Accounting and Financial Reporting

ISSN 2162-3082

2018, Vol. 8, No. 2

included middle and senior IT managers such as CIO and department directors. Altogether 9 interviews were conducted with 9 interviewees. Each interview lasted an average of 90 minutes. For both cases, interview questions were open-ended and based on topic guides. Each informant was assured of the confidentiality of the data provided, especially when sensitive information was sought (Walsham, 2006). Interviews were digitally recorded and transcribed for subsequent data analysis. Site visits to the companies' facilities were arranged. Whereas the interviews formed the primary source of data, they were corroborated by other secondary data such as internal publications, organizational documents and field notes. Control and social capital theories guided the design of the interview questions. These interviewees represent various "voices" which is important for triangulation purpose (Walsham, 2006).

\subsection{Data Analysis}

We carried out data analysis by recursively iterating between the empirical data, the theoretical lens, and the relevant control and social capital literature. The iteration helped to shape our findings. We continued the iterative process until the state of theoretical saturation was reached, that is, when it was possible to comprehensively explain the findings of the case study, and no additional data needed to be collected to improve the developed prototypes. Our analysis included reading all transcripts and documents, highlighting the descriptions and developing a list of themes that covered formal control, informal control and social capital attributes during the IS implementation process (Refer to Table 2 below).

Table 2. Excerpts of coding categories

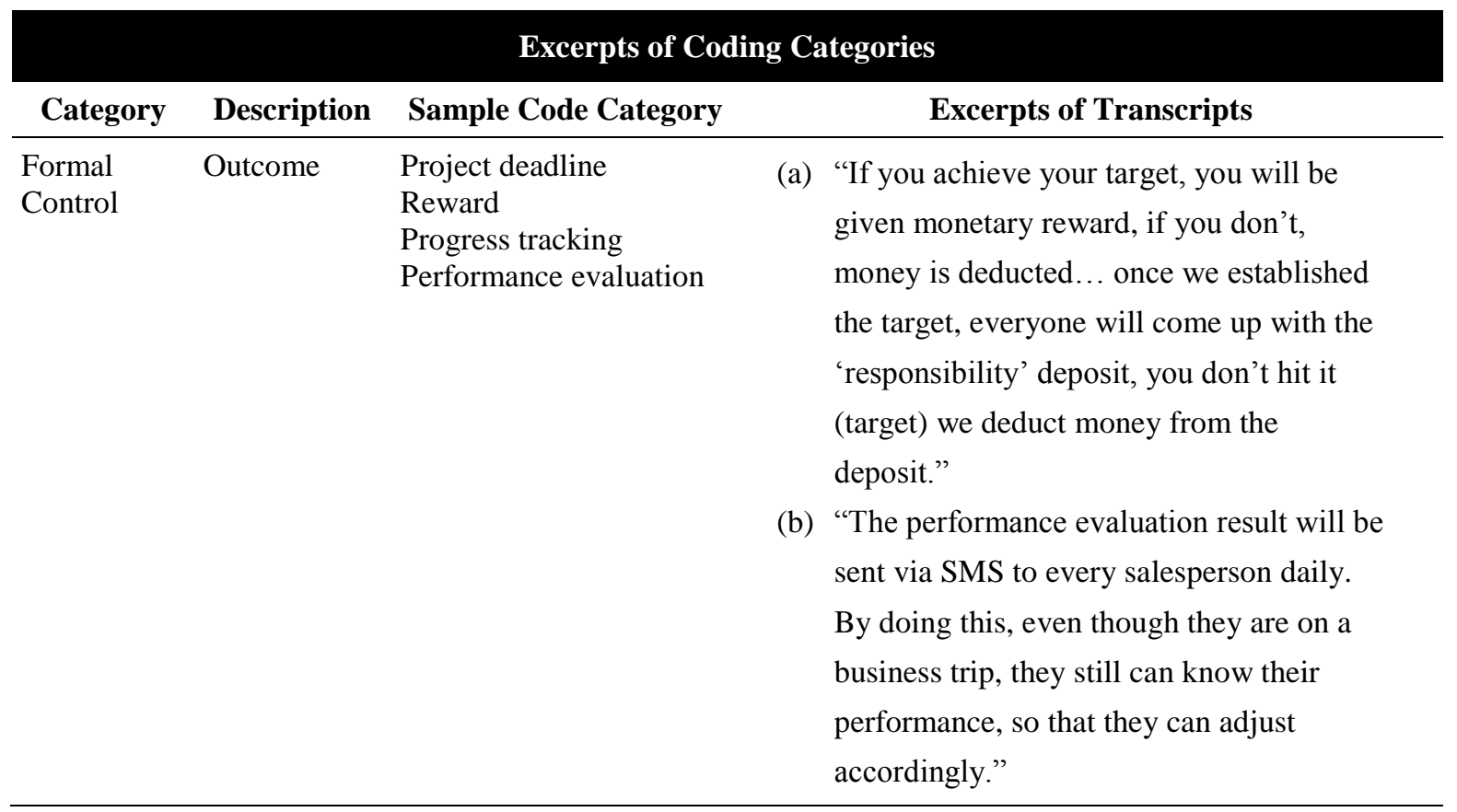




\section{Macrothink}

International Journal of Accounting and Financial Reporting

ISSN 2162-3082

2018, Vol. 8, No. 2

\begin{tabular}{lll}
\hline Formal & Behavioral & Rules \\
Control & & Procedures
\end{tabular}

(a) Decision-making is conducted automatically by the system. This allows the company to design clear rules and procedures as well as implement performance evaluation system. Establishment of clear rules and procedures enables division of the complex task into smaller and simpler ones.

\begin{tabular}{lll}
\hline Informal & Clan & Clan relationship \\
Control & & Clan culture
\end{tabular}

(a) The informal mentor-apprentice relationships, whereby past AODB administrators (who were not directly involved in this project) served as mentors to the AODB administrator who were involved in the project.

\begin{tabular}{lll}
\hline Social & Structural & Connections \\
Capital & & Network ties \\
Attribute & & Configuration
\end{tabular}

(a) The setup of project steering committee symbolizes authority and the reporting structure, meetings and procedures.

(b) The project manager was well-respected by everyone in the company for his extensive technical and business knowledge, strong communication, relationship management, and improvisation capabilities. Through close discussion with all the users, the project manager was able to secure their buy-ins and commitment.

\begin{tabular}{lll}
\hline Social & Cognitive & Shared meaning \\
Capital & & Shared understanding \\
Attribute & &
\end{tabular}

(a) "Through these vendor trainings, we imparted our company's management methodology, procedures, norms, including our existing system operations details and things to look out for during requirement study. We wanted them to meet the quality of work standards similar to us. Make their thought patterns, beliefs, and work attitudes to be in sync with us".

\begin{tabular}{lll}
\hline Social & Relational & Trust \\
Capital & & Norms \\
Attribute & &
\end{tabular}

(a) There was a long history of working relationship between the IT project team and the AODB administrators. Their relationship started in 1999 when they worked in the same project team to implement AODB projects in Terminals 1 and 2 .

Coding categories reflect our interpretations of the enacted controls and social capital assets available during IS implementation. We conducted an initial pilot run for coder training and pilot testing of reliability. During the pilot run, we also refined the coding instrument and 
procedures. To establish the reliability of the coding, each coder was asked to quote a particular segment of the relevant texts. Coding was conducted independently and without consultation and guidance. We examined the portions of the codings where both coders agreed and measured the inter-coder reliability using Cohen's Kappa coefficient. Our coefficient score of 0.76 suggests substantial agreement between the two coders, and the result also demonstrates that the categories were clearly defined and could be located in the text with little ambiguity. As the reliability coefficient was high, each coder was subsequently asked to code separate portions of the texts. We sorted relevant interview comments and secondary reports according to the various categories and developed a list of themes within each category (Harris, 2001). The list contained the location of each comment on the transcript, the transcript number, the interview date, any links to other comments, reports, and sources of news coverage. The next step in our analysis was to analyze the formal control, informal control and social capital attributes in each case and subsequently, compare across both cases. This led us to derive social capital-control relationships and moderating effects (described in the Within-Case and Cross-Case Analysis Sections). In order to reduce researcher bias, a senior colleague was asked to take part in early analysis of some of the data. The colleague was uninvolved in the fieldwork and was, therefore, unfamiliar with both cases. The role of this colleague was to bring a different and possibly more objective eye to the evidence and detect any bias in data analysis.

Overall, our findings revealed patterns that conformed to the control, social capital, and IS implementation literature in that the importance of social capital assets and controls was underscored in each case. But our findings go beyond the existing work by uncovering two social capital-control relationships and the moderating effects that had yet to be explored in existing Control and social capital literature. The next section presents the background information of the two cases, describes the events that happened, and analyzes how social capital assets and controls were managed during IS implementation.

\section{Case Description and Analysis}

\subsection{Within-Case Analysis}

In this section, we will highlight the major IS implementation activities and the controls enacted in Beijing Capital International Airport Terminal 3 and Haier projects. Interestingly, both companies adopted a different control approach. While BCIA adopted a good mix of both formal and clan controls, Haier relied heavily on formal controls.

\section{Case 1: Beijing Capital International Airport Terminal 3}

Beijing Capital International Airport (BCIA) Company Limited is a state-owned enterprise that manages Beijing Capital International Airport in Beijing, China. The airport has three airport terminals, namely Terminals 1,2 and 3. Terminal 3 was specially designed and constructed for the 2008 Olympics. Our study focused on how BCIA implemented Airport Operation Database (AODB), Airport Departure, Airport Security and Airport Data Center systems. The development of these systems started in 2005-2006 period and completed in early 2008. 
$A O D B$ system - The AODB system is an integrated platform that supports the entire airport terminal's systems. Given the complexity of the project, the IT manager dispatched key AODB administrators (who were both eventual system users and members of the AODB project team) to visit established Airport Terminals in the world (e.g. Singapore's Changi Terminal) so as to acquire new insights to AODB system management. These visits allowed the administrators to learn: (1) a comprehensive methodology of managing AODB system that also laid the foundation for the future administration and maintenance of AODB system; (2) the motivation of setting up two Terminal Command Centers that consolidated all existing AODB-related system and terminal operations for more effective operational management; and (3) the ability to craft out tender requirements that were highly pre-emptive in mitigating potential uncertainties and inherent risks. According to the IT manager:

"In 2000, I took the lead with a few other colleagues to look into system backup and business continuity in-depth study (for the AODB) ... during that time, we didn't leverage upon outside help and we did all the research on our own ... From 2000 to 2002, we came up with a maintenance standard operation procedure handbook. Till today, our maintenance strategy is dependent on this handbook."

The project team met challenges both in integrating the two AODB systems and the AODB system and the Airport Transport Control (ATC) system. The culture of learning and sharing was nurtured and reinforced throughout the project. For instance, the informal mentor-apprentice relationships, whereby past AODB administrators (who were not directly involved in this project) served as mentor to the AODB administrator in charge of this project. Proactive problem-solving behavior was best exemplified through the pre-emptive development of a highly flexible component in the AODB systems that could accommodate all kinds of changes anticipated in the upgrading of ATC system.

Airport Departure System - The Airport Departure System's main functionality is to 'hook up' airlines' departure systems and support passenger check-in and boarding processes. One issue faced by the project team was that the vendor was maintaining its proprietary software overseas, which made it difficult to control the speed of project implementation and the quality of customization works. According to a project team member:

"The vendor guards their technical knowledge very strictly... and because their technology is proprietary and not open-sourced ... we honestly feel that this is not a healthy development into our future relationship".

In order to mitigate the risk of schedule slips, vendors were put through a series of training sessions conducted by the IT project team. These training sessions were designed to impart important information pertaining to BCIA's culture, work practices and standards. According to the IT manager: 


\section{MInstitute ${ }^{\text {Min }}$}

International Journal of Accounting and Financial Reporting

"Through these vendor trainings, we imparted our company's management methodology, procedures, norms, including our existing system operations details and things to look out for during requirement study. We wanted them to meet the quality of work standards similar to us. Make their thought patterns, beliefs, and work attitudes to be in sync with us".

A rigorous and detailed 'Backward Planning' methodology (interpreted as setting hard deadline and planning backward for milestones) was adopted to communicate expected deliverables and their deadlines to the vendor. Weekly project meetings were held to track the project progress and findings were presented to the project steering committee. The role of the project steering committee was to identify and interpret user requirements and monitor vendor's performance. With the help of project steering committee, the IT project team was able to keep the project on schedule amidst a large amount of customization works and user-requested changes. According to a project team member:

"The work plans were very clear - we had daily work details, some even up to every few hours. If the work on that day could not be completed, everyone would have to do over-time".

Airport Security System - Due to the sheer size of Terminal 3 and the complexity of the airport security system, the level of collaborations among project stakeholders was also unprecedented. The IT project team developed multiple channels of communications such as the use of 'encouragement slogans' to motivate project stakeholders. For instance, a project member suggested:

"With regard to work culture ... the slogan in our canteen can best represent that and it says 'If you are afraid of death, don't become a communist. If you are afraid of hard work, don't take up system development work of T3!'

These measures were effective in instilling sense of pride in project team members for associating with the system implementation. The IT project team also developed practices that would promote risk taking and problem-solving to resolve any unforeseeable situations that may occur during project implementation. According to the IT manager:

"If you achieve your target, you will be given monetary reward, if you don't, money is deducted... once we established the target, everyone will come up with the 'responsibility' deposit, you don't hit it (target) we deduct money from the deposit. You complete it, we give you reward. (promote risk-taking measure)"

Interestingly, an independent audit team was set up to inspect the project deliverables. Without endorsement by the audit team, the subsequent implementation of the system could not proceed. Progress meetings were held on weekends and site inspections were often conducted at night to ensure the project was on track. According to the business manager:

"We have a change management process that is very stringent. Any change (proposed by vendor/users) needs to go through the engineer in the audit team. 
Only when there is sufficient evidence then it goes up to our change management committee for approval".

Airport Data Center System - The system serves to collate all terminal operations related data from the various airport systems so as to provide information to aid decision making. The system is concerned with generating billing details. Hence, it must be accurate and error-free otherwise bills generated from the system would not be trusted by BCIA customers (namely, airlines and shop owners in Terminals), which are main users of Airport Data Center System. The IT department had appointed one of the well-respected IT staffs within the airport as the project manager. The project manager was well-respected by everyone in the company for his extensive technical and business knowledge, strong communication, relationship management, and improvisation capabilities. When the project was implemented, the project manager immediately executed a comprehensive communication plan. The plan was set to align all users' interests towards fulfilling the accounting regulatory requirements mandated by the Chinese Government and to promote the key benefits of the new system. Through close discussion with all the users, the project manager was able to secure their buy-ins and commitment. As changes to the system requirements were expected, the project manager instituted a rigorous change management procedure to control change. He was able to do this because he was given complete authority and autonomy to run this project.

Due to the ambitious project deadline, the project manager leveraged upon his close working relationships with the local partners of the outsourced vendor to start the project before the signing of the contract. This had serious consequences because the outsourced vendor, company CX (a large multinational company), had decided to exit the project (because the company had decided to pull out from China market) before the project implementation commenced. The project manager managed to convince the BCIA's management to award the contract to a local partner of the outsourced vendor, Company LP. Weekly project meetings involving all key users and company LP's team were held.

"For this project, every week we have one ... everyday, the project manager (vendor) would analyze the work progress of every item in this project. Since there is WBS (work breakdown structure) ... you can verify the progress of all the tasks using it (WBS). Every week they (vendor) need to present the report (during the meeting)".

Project requirement changes and progress were meticulously tracked and reported during these meetings. While users raised several requirement change requests, the IS project manager was able to persuade them to either delay the requests after 2008 or forgo the change requests. Notably, measures undertaken by the project team had kept the project scope in check and the project on schedule.

"If you let users control the process, you will face the challenge of frequently changing requirements ... because they (users) would have their own interest." 


\section{Case 2: Haier Group}

Order Management System - Haier is the largest household appliance manufacturer in China with over 240 subsidiaries, more than 110 design centers, production plants and trading companies globally. As a manufacturer, the order fulfillment process is core to the company. Every month, the company receives more than 0.9 million sales orders. These orders involved more than 10,000 types of customized products, which require procuring more than 260,000 types of material. Throughout the order fulfillment process, there are many operational decisions to be made. Several information that include customer requests, raw materials, end products and the production process are generated to support management decision-making. Part of Haier's rapid growth is its ability to reduce the duration of the order fulfillment process from two months to two weeks.

Many information systems are implemented to facilitate information exchange between salespersons and the headquarters. One example is the order management system. In the past, information on customer demands gathered by salespersons turned obsolete and distorted because of many hierarchical levels. The order management system solves this problem by enabling direct information exchange between salespersons that are close to local market and sales department in the headquarters. So information distortion would be largely eliminated. The headquarters also provide daily feedback information to salespersons via Short Messaging Service (SMS). As a result, salespersons and the headquarters exchange information more frequently. According to the Manager of Strategy Department:

"The performance evaluation result will be sent via SMS to every salesperson daily. By doing this, even though they are on a business trip, they still can know their performance, so that they can adjust accordingly."

Based on records of salesperson's performance from the order management system, the company would evaluate salesperson's performance and classify it based on the extent to which it is consistent with organizational goals. According to a Business Manager:

"If you can fulfill your plan completely, you can get all your salary and season rewards. If you want to get your salary, you have to make a sound sales plan, to sell profitable products and to sell fast. Evaluation toward employees' performance is characterized by personal, immediate, quantitative, open, outcome-driven, monetary positive incentives and "negative incentives". Employee's salary is calculated according to goal fulfillment and performance."

Through above practices, accurate and timely information is delivered to sales department and salespersons so that they become more sensitive to market changes. With this information, more accurate sales decisions could be made. Information systems developed to support decision-making in this task center on facilitating tight information exchange and integration across departments. Based on the information integration pattern established, the company was able to design a series of clear procedures for coordination and better nurture the collective culture across departments. A series of clear procedures helped to guarantee sufficient communication and smooth potential conflicts across departments. These 
procedures formulated concrete time and activities to be performed by specific department as well as individual. For instance, the company conducted routine cross-departments meeting every Wednesday to communicate and negotiate sales and production issues. According to a Business Manager:

"We have a set of procedures and mechanisms to cope with coordination between sales and operation. Sales persons will report results of order prediction on every Monday; the headquarters will adjust the results of order prediction on every Tuesday; then estimate short-term order prediction on every Wednesday; estimate long-term order prediction on each Friday."

Besides formal mechanisms, Haier would propagate common organizational value across departments and obedience to "one common goal" of the company. It was promoting the belief that individuals would benefit more by accomplishing the company goal.

Global Value System - One of Haier's major challenges is to fulfill large production orders in a short time by assembling a significant number of raw materials. The company's enterprise resource planning system, which is named "Global Value System (GVS)", played a pivotal role in processing raw material, product and the production process information. The system would further arrange a production plan for each plant based on information of that particular plant. Thus, decision-making was conducted automatically by GVS. This would allow the company to design clear rules and procedures as well as implement performance evaluation system. Although the production task was complicated, establishment of clear rules and procedures enabled division of the complex task into smaller and simpler ones. These rules and procedures pre-specified detailed processes to be followed by individuals. Furthermore, the performance of employees would be evaluated based on certain evaluation criteria and salary was influenced by the outcomes of the evaluation. Evaluation criteria, such as delivery on time and accuracy of order delivery, helped to push employees toward raising efficiency.

\subsubsection{Summary}

Our within-case analysis suggests that while BCIA implemented formal and informal controls during project implementation, Haier relied more on formal controls. Table 3 below provides a summary of control modes in the within case analyses. Next, our cross-case analysis will compare and contrast the relationship types in terms of social capital attributes and formal as well as informal control modes. In so doing, we will abstract the concepts from the within-case analysis and develop a framework of three social capital-control relationship types. 


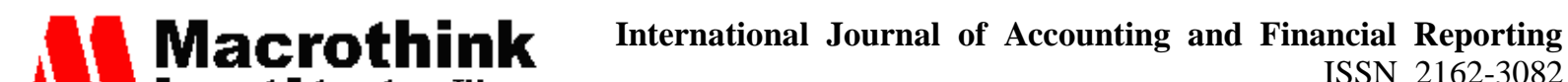 $\Lambda$ Institute"'

Table 3. A summary of control modes in BCIA and Haier cases

\begin{tabular}{|c|c|c|c|}
\hline \multirow{2}{*}{ Case } & \multicolumn{2}{|c|}{ Formal } & \multirow{2}{*}{$\begin{array}{c}\text { Informal } \\
\text { Clan }\end{array}$} \\
\hline & Outcome & Behavioral & \\
\hline \multirow[t]{3}{*}{ BCIA } & $\begin{array}{l}\text { Airport Departure System - } \\
\text { Setting hard deadline; close } \\
\text { tracking of project progress }\end{array}$ & $\begin{array}{l}\text { AODB - Maintenance standard } \\
\text { operation procedure handbook }\end{array}$ & $\begin{array}{l}\text { AODB - Strong learning } \\
\text { culture; Close } \\
\text { mentor-apprentice } \\
\text { relationships }\end{array}$ \\
\hline & $\begin{array}{l}\text { Airport Security System - } \\
\text { Monetary reward; } \\
\text { 'responsibility deposit'; close }\end{array}$ & $\begin{array}{l}\text { Vendor training (BCIA's } \\
\text { culture, work practices and } \\
\text { standards) }\end{array}$ & $\begin{array}{l}\text { Airport Security System - } \\
\text { Work culture }\end{array}$ \\
\hline & $\begin{array}{l}\text { tracking of project progress by } \\
\text { independent audit team }\end{array}$ & $\begin{array}{l}\text { Airport Data Center System - } \\
\text { rigorous change management } \\
\text { procedure }\end{array}$ & $\begin{array}{l}\text { Airport Data Center System } \\
\text { - Well respected IT manager } \\
\text { with complete authority and } \\
\text { autonomy; close relationship } \\
\text { with vendor }\end{array}$ \\
\hline \multirow[t]{2}{*}{ Haier } & $\begin{array}{l}\text { Order Management System - } \\
\text { Daily performance evaluation } \\
\text { and feedback (salary and } \\
\text { season rewards) }\end{array}$ & $\begin{array}{l}\text { Order Management System - } \\
\text { Clear procedures for } \\
\text { communication and conflict } \\
\text { resolution }\end{array}$ & $\begin{array}{l}\text { Order Management System } \\
\text { - Collective culture }\end{array}$ \\
\hline & $\begin{array}{l}\text { Global Value System - } \\
\text { Performance evaluation with } \\
\text { clear goals }\end{array}$ & $\begin{array}{l}\text { Global Value System - } \\
\text { Pre-specified rules and } \\
\text { procedures (automatic } \\
\text { decision-making) }\end{array}$ & \\
\hline
\end{tabular}

\subsection{Cross-case Analysis: Theoretical Synthesis}

As depicted in Figure 1 below, the two social capital-control relationship types derived from our analysis vary according to various control modes. The three social capital attributes are associated with both formal and informal controls but play a vastly different role in the enactment of controls: supplementary and synergistic. Some of or all three social capital attributes also interacted to affect the nature and extent of enacted controls. 


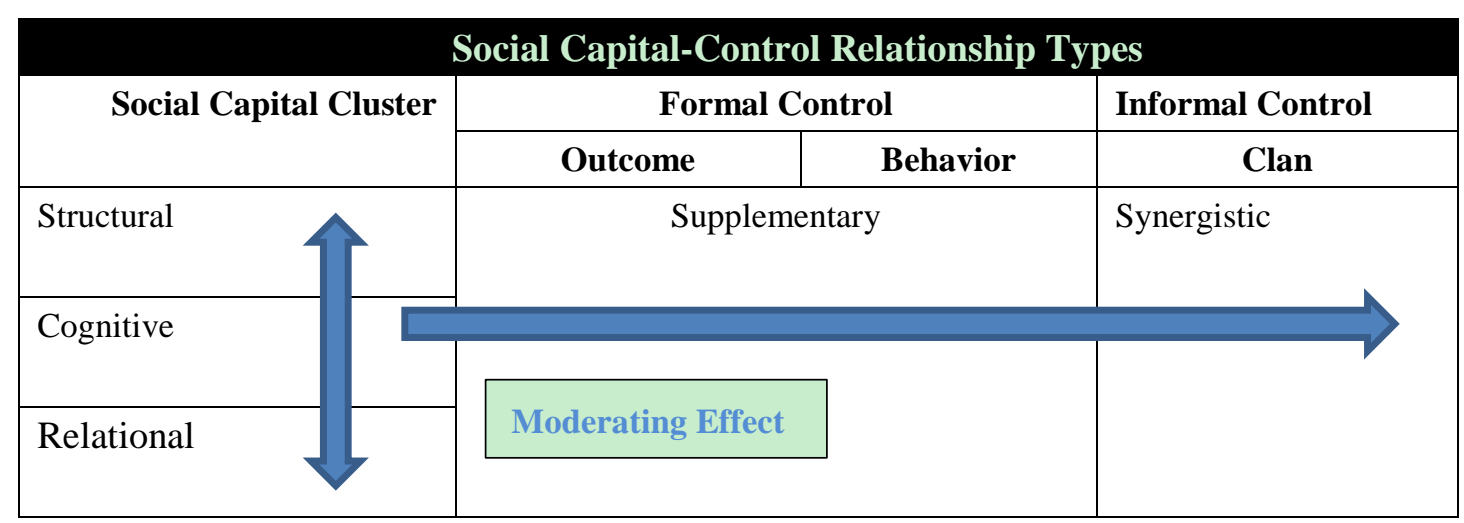

Figure 1. Social capital-control relationship types

\subsubsection{Social Capital-Formal Control Relationship: Supplementary}

In both cases, outcome and process controls were vastly implemented. For instance, to ensure the fulfillment of the tight project deadline in the BCIA's case, several outcome controls were enacted. These control mechanisms were: setting hard deadlines, close tracking of project progress and the 'responsibility deposit scheme'. We posit that these controls helped to keep the schedule and scope in check. In the case of Haier, the outcome controls include higher salary and season rewards, and daily performance evaluation and feedback with clear goals. These outcome controls were appropriate in both cases because outcome could be clearly identified (Kirsch, 2004) and in BCIA's case, had to be achieved. While most outcome controls do not mandate a detailed process to be followed and encourage flexibility in identifying new and unique solutions for problem solving, but when adopted concurrently with behavioral controls, flexibility may be limited. BCIA specified the appropriate behaviors and processes in which the IT project teams and vendors ought to engage in the project. These control mechanisms include maintenance standard operation procedure handbook, vendor training sessions and rigorous change management procedures. A good example of how social capital may have a supplementary relationship with outcome and process controls is the setup of a project steering committee comprising subject-domain experts from airlines and the IT department.

The project steering committee symbolizes authority and the reporting structure, meetings and procedures may be considered a form of 'hierarchical control' (Aulakh et al., 1997). The purpose of the committee was to influence its stakeholders to exercise the appropriate behaviors during task execution with the aim of achieving eventual outcome (Fink \& Neumann, 2007). This is demonstrated in the case through the way in which: (1) the technical lead had managed to align all the interest of members of the project steering committee towards the shared goal of enhancing passenger's departure experience; and (2) the training programme for the vendor was conducted to infuse BCIA's culture, practices and norms. The setup of IT project steering committee had helped in the establishment of a trusting relationship between the IT project team and the eventual system users. This relationship allowed the task-related outcomes and behaviors during system or change request 
implementation to be accurately defined. The specified behaviors had also limited the vendor's opportunistic behaviors. Overall, the setup of IT project steering committee and the vendor training to inculcate shared ideology allowed BCIA to implement both outcome and behaviour controls, which played a fundamental role in its project completion.

Similarly in the case of Haier, two behavioral controls were implemented: clear procedures for communication and conflict resolution, and automatic decision-making process. Interestingly, Haier's findings contrast with Nidumolu and Subramani's (2003) argument on standardisation of methods and standardisation of performance criteria in enactment of control. While Haier achieved success with complete standardisation of methods and performance criteria, Nidumolu and Subramani's (2003) findings suggest that performance is enhanced by establishing uniform performance criteria across projects (standardization of performance criteria) while giving each project team the authority to make decisions with respect to methods (decentralization of methods). The standardisation structure at Haier certainly helped to enhance behavioural control in that it integrated multiple autonomous, diversely skilled parties to create complex products and services (Clark \& Fujimoto, 1989). The common knowledge of rules and procedures enhanced project team members' ability to understand and predict others' behavior and develop trust over time (Geringer \& Hebert, 1989).

\subsubsection{Social Capital-Clan Control Relationship: Synergistic}

Our data revealed a long history of working relationship between the IT project team and the AODB administrators. Their relationship started in 1999 when they worked in the same project team to implement AODB projects in Terminals 1 and 2. In addition, the informal mentor-apprentice arrangement made by the AODB administrators also strengthened the rapport and bonding among the project team members. This is supported by the extant literature on organization control that concurs such interpersonal connections and open communication may instill trust, norms and cooperative behaviours (Stewart and Gosain 2006) among project stakeholders, and ultimately leading to project success.

Shared ideology, also played instrumental role in the case. The IT project team had developed comprehensive communication plans to nurture the development of a shared ideology among project's stakeholders. This was important to generate the bonding and trust among the project team members because shared ideology may create an attractive identity and a collective interpretation of reality shared by project stakeholders (Van den Bosch et al., 1999). Past research has highlighted the important process of having project team members to achieve a shared understanding among all project stakeholders through interaction, sense-marking and collective learning (Ayas \& Zeniuk, 2001). This was also evident throughout the project especially in the initial tender proposal stage where the IT project team had spent a significant amount of time in making overseas visits before coming up with the eventual tender specification. These visits helped the IT project team to align the project's stakeholders towards a common purpose which enables the integration of social relationships critical to respond to the uncertainties inherent in a project (Slaughter \& Kirsch, 2006). The ability in creating a collaborative environment (through shared ideology) has a positive effect 
on the team's ability in accommodating changes in systems without incurring significant penalty in time and cost (Fink \& Neumann, 2007). Ultimately, people are guided by their shared values and norms and they may voluntarily behave in a manner that is desired by other organizational members. Socialization provides much needed interaction among members from BCIA and the IT vendor, thus enabling managers to familiarize themselves with their partner's organizational culture. Such shared understandings among members certainly helped to encourage mutual trust and cooperative problem solving.

In addition, the level of trust between the project manager and the project team members as well as the vendor was high. This was helped by the fact that the management of BCIA had appointed a well-respected expert as the project manager. It was noted that the project team members trusted him professionally owing to his extensive technical and business knowledge and also viewed him a close associate. Furthermore, because he was given complete authority and autonomy to run the project, the project manager was able to secure their buy-ins and commitment. Overall, it was evident from the case facts that trusts certainly added a synergistic effect to clan control. This corroborates existing research that trust may also be manifested in contractual flexibility. For instance "relational contracting" arises because of existence of trust that makes incomplete contracts conceivable. When partners trust each other, they are in a better position to appreciate the benefits of contractual flexibility, which include faster response and more efficient environmental adaptation. Trust enables the cohesiveness and comfort needed for open and thoughtful interactions (Das \& Teng, 1998).

\subsubsection{Moderating Impact of Social Attributes Interaction on Social Capital-Control Relationship}

We observed the existence of moderating impacts of social capital cluster interaction on the social capital-control relationships. For example, structural attribute moderated the relationship between relational social capital as well as behavioral control. While Haier enacted its clan control by propagating organizational value of "one common goal" across departments, the level of trust and bonding among employees were hampered by its pre-specified rules and procedures embedded within its automatic decision-making system. This is an important issue because if the level of trust is high, Ring and Van de Ven (1994) suggest that formal controls may even be substituted by psychological contract (trust) in any form of cooperation. Sitkin and Roth (1993) report limited effectiveness of legalistic remedies (i.e., formal rules and contracts) for building trust. Hence it appears that the nature of formal controls is at odds with a trusting environment, which suggests a negative relationship between formal control and trust level.

Another example of moderating effect is cognitive social capital moderated the relationship between relational social capital and clan control in the case of BCIA. The aim of establishing more trust and rapport between the IT project team and the vendors would not be possible if vendors were not trained and learned about BCIA's culture, work practices and standards. The shared ideology certainly played a key role in integrating the diverse backgrounds and mindsets of the IT project team and vendor. This finding is in line with Oh et al. (2006) who suggest a group's level of closure is defined by the characteristics of the 


\section{MInstitute Macrothink $_{\text {Int }}^{\text {Intis }}$}

International Journal of Accounting and Financial Reporting

ISSN 2162-3082

2018, Vol. 8, No. 2

relationships among group members. Part of the relationship ties is influenced by the fact that whether group members share common values, practices and goals. This is especially true when the focus is on the ability to draw upon the group's collective knowledge, rather than that of one individual. Strong-closure group would benefit from greater cooperation and greater conformity to norms, thus leading to better management of group effectiveness.

The cognitive cluster of social capital also has moderating impact on the relationship between relational social capital and behavioral control in the case of BCIA. Vendor's training played a key role providing the basis for developing a shared understanding of the task at hand (Nelson \& Cooprider, 1996). By understanding and embracing BCIA's culture, work practices and standards, there is less need for formal specifications of behaviors because team members develop a tacit understanding of what needs to be done and over time, may well leverage social capital assets to facilitate control within project teams (Kirsch et al., 2010).

\section{Implications and Conclusion}

In this paper, we examined social capital and control relationships in IS implementation by drawing upon social capital and control theories. By understanding the dynamics of social capital-control relationships, organizations can leverage social capital assets to facilitate control within IS projects. Our findings are based upon two IS implementation cases. Our analysis revealed two types of social capital-control relationship - supplementary and synergistic. We also identified moderating effects on the social capital attributes interaction on the relationship with formal as well as informal controls. Our research has several implications for the enactment of control within IT implementation. Through case analysis of the findings of two IS implementation projects, we have achieved our research objectives.

First, while much has been discussed about social capital and clan control, relatively little is known about the relationships between social capital and the formal as well as informal controls. Our study found that social capital attributes have a supplementary relationship with formal controls and a synergistic relationship with clan controls. Future research may examine the nature and extent of the supplementary and synergistic relationships between social capital and formal controls as well as informal controls. For example, which of structural, cognitive and relational attribute has the highest 'supplementary power' or 'synergistic power'? Also, under what conditions are they facilitated?

Second, our study observed the existence of moderating impacts of social capital cluster interaction on the social capital-control relationships, specifically behavioural and clan controls. For instance, our case findings suggest the moderating impact structural attribute had on the relationship between relational social capital and behavioral control. This is a new finding because little is known about the moderating effects. Future research may examine if there is any moderating effect social capital interaction on relationship with outcome controls.

The findings of this study should be viewed within the context of its limitations. We had to rely on the interviewees' retrospective view of the case (memory traces). A disadvantage of retrospective responses is that they might be affected by errors of recall (Glick et al., 1990). 


\section{Mll Macrothink}

International Journal of Accounting and Financial Reporting

ISSN 2162-3082 2018, Vol. 8, No. 2

For example, informants might selectively neglect some events that are important or focus on trends that are actually unimportant but conspicuous to them at the time of the interview. To minimize errors of recall, we have observed the following procedural safeguards: (1) Interviews explicitly focused on major events that could be recalled more reliably. (2) All key informants were key project stakeholders who had been personally involved in or had been close observers of the important events and processes that they were reporting on. (3) We used cross-checking of reports between the stakeholders without privileging one over another. (4) The interviews were conducted shortly after the cessation of the project. Each of these safeguards has been recommended to minimize errors of recall (Glick et al., 1990).

Despite its limitations, we believe that our study has produced a useful examination of social capital-control relationships that offers a vocabulary for framing experiences and learning how a project group could utilize social capital resources during enactment of controls in IS implementation. We believe that it is important for organizations to better understand the social capital-control relationships to ensure project progress and success especially when team members, as well as team managers, can leverage social capital assets to facilitate control within IS projects.

\section{References}

Adler, P.S., \& Kwon, S.W. (2002). Social Capital: Prospects for a New Concept. Academy of Management Review, 27(1), 17-40.

Ashurst, C., Doherty, N., \& Peppard, J. (2008). Improving the Impact of IT Development Projects: the Benefits Realization Capability Model. European Journal of Information Systems, (17), 352-370.

Barki, H., Rivard, S., \& Talbot, J. (1993). Toward an Assessment of Software Development Risk. Journal of Management Information System, (10), 203-225.

Bourdieu, P. (1986). The Forms of Capital. In J.G. Richardson (Ed.), Handbook for Theory and Research for the Sociology of Education (pp. 241-258).

Choudhury, V., \& Sabherwal, R. (2003). Portfolios of Control in Outsourced Software Development Projects. Information Systems Research, 14(3), 291-314.

Chua, C., Lim, W.K., Soh, C., \& Sia, S.K. (2012). Enacting Clan Control in Complex IT Projects: a Social Capital Perspective. MIS Quarterly, 36(2), 577-600.

Cohen, W.M., \& Levinthal, D.A. (1990). Absorptive Capacity: a new perspective on learning and innovation. Administrative Science Quarterly, 35(1), 128-152.

Das, T.K., \& Teng, B.S. (1998). Between Trust and Control: Developing Confidence in Partner Cooperation in Alliances. Academy of Management Review, 23(3), 491-512.

Eisenhardt, K. (1985). Control: Organizational and Economic Approaches. Management Science, 31(2), 134-149. 


\section{MInstitute Macrothink $_{\text {Int }}$}

International Journal of Accounting and Financial Reporting

ISSN 2162-3082

Hansen, Y.M. (2002). Knowledge Networks: Explaining Effective Knowledge Sharing in Multiunit Companies. Organization Science, 13(3), 232-248.

Harris, H. (2001). Content analysis of secondary data: a study of courage in managerial decision making. Journal of Business Ethics, 34(3/4), 191-208.

Inkpen, A.C., \& Currall, S.C. (2004). The Coevolution of Trust, Control, and Learning in Joint Ventures. Organization Science, 15(5), 586-600.

Inkpen, A.C., \& Tsang, E.W.K. (2005). Social Capital, Networks and Knowledge Transfer. Academy of Management Review, 30(1), 146-165.

Jiang, J.J., \& Klein, G. (1999). Risk to Different Aspects of System Success. Information \& Management, (36), 263-272.

Kappelmana, L., Mckeemanb, R., \& Zhang, L. (2006). Early Warning Signs of it Project Failure: The Dominant Dozen. Information Systems Management, 23(4), 31-36.

Keil, M., Tan, B., Wei, K., Saarinen, T., Tuunainen, V., \& Wassenaar, A. (2000). A Cross-Cultural Study on Escalation of Commitment Behavior in Software Projects. MIS Quarterly, 24(2), 299-324.

Kirsch, L. (1996). The Management of Complex Tasks in Organizations: Controlling the Systems Development Process. Organization Science, 7(1), 1-21.

Kirsch, L. (1997). Portfolios of Control Modes and IS Project Management. Information Systems Research, 8(3), 215-239.

Kirsch, L. (2004). Deploying Common Systems Globally: The Dynamics of Control. Information Systems Research, 15(4), 374-395.

Kirsch, L., Ko, D.G., \& Haney, M. (2010). Investigating the Antecedents of Team-Based Clan Control: Adding Social Capital as a Predictor. Organization Science, 21(2), 469-489.

Liu, Y.C., Chen, H.G., Jiang, J.J., \& Klein, G. (2010). Task Completion Competency and Project Management Performance: The Influence of Control and User Contribution. International Journal of Project Management, (28), 220-227.

Mähring, M. (2002). IT Project Governance. Economic Research Institute, Stockholm School of Economics, Stockholm, Sweden.

Nahapiet, J., \& Ghoshal, S. (1998). Social Capital, Intellectual Capital, and the Organizational Advantage. Academy of Management Review, 23(2), 242-266.

Ouchi, G. (1980). Markets, Bureaucracies and Clans. Administrative Science Quarterly, (25), 129-141.

Putnam, R. D. (1993). Making democracy Work: Civic traditions in modern Italy. Princeton: Princeton University Press. 


\section{Macrothink \\ International Journal of Accounting and Financial Reporting ISSN 2162-3082 2018, Vol. 8, No. 2}

Rustagi, S., King, W., \& Kirsch, L. (2008). Predictors of Formal Control Usage in IT Outsourcing Partnerships. Information Systems Research, 19(2), 126-143.

Tiwana, A., \& Keil, M. (2007). Does Peripheral Knowledge Complement Control? A Study of Technology Outsourcing Alliances. Strategic Management Journal, 28(6), 623-634.

Tsai, W., \& Ghoshal, S. (1998). Social Capital and Value Creation: The Role of Intrafirm Networks. Academy of Management Journal, 41(4), 464-476.

Walsham, G. (2006). Doing Interpretive Research: Nature and Method. European Journal of Information Systems, (15), 320-330.

Yin, R.K. (2003). Case Study Research: Design and Methods (3rd ed.). Sage Publications, Beverly Hills, CA.

\section{Copyright Disclaimer}

Copyright for this article is retained by the author(s), with first publication rights granted to the journal.

This is an open-access article distributed under the terms and conditions of the Creative Commons Attribution license (http://creativecommons.org/licenses/by/4.0/) 